\title{
Prevalence, Awareness, Treatment, and Control of Dyslipidemia among Adults in Beijing, China
}

\author{
Li Cai ${ }^{1}$, Lei Zhang ${ }^{2}$, Aiping $\mathrm{Liu}^{3}$, Shuping $\mathrm{Li}^{4}$ and Peiyu Wang ${ }^{3}$
}

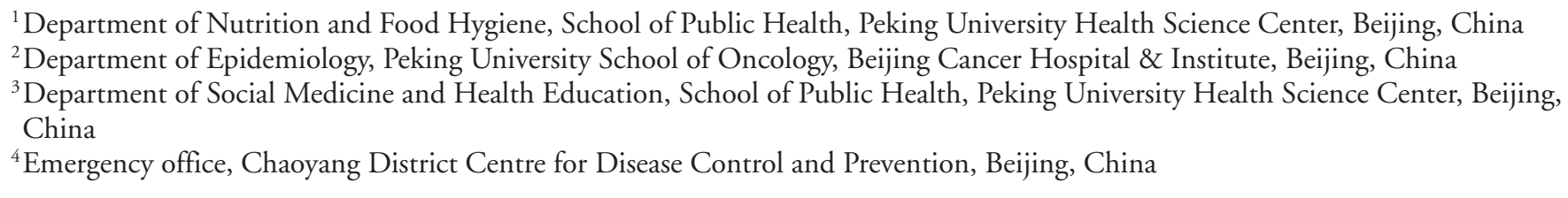

Aim: The present study aimed to determine the up-to-date prevalence, awareness, treatment, and control of dyslipidemia, and their distribution and related influencing factors in adults in Beijing, China.

Method: A cross-sectional study was conducted in 2008, using a four-stratified cluster sampling. Data from a questionnaire, physical examination, and blood sampling were obtained from 5761 adults aged 18-79 years.

Results: The prevalence of high TC, high LDL-C, low HDL-C and TG was $12.2 \%, 17.9 \%, 12.0 \%$ and $15.1 \%$, respectively. The prevalence of dyslipidemia was $35.4 \%(42.9 \%$ in men and $30.1 \%$ in women), and was similar in rural $(35.3 \%)$ and urban $(35.8 \%)$ areas. Dyslipidemia was associated with male gender, age, a family history of dyslipidemia, education at college or above, current smoker, overweight and obesity, intermediate and high waist circumference, hypertension and diabetes. Among all participants with dyslipidemia, $22.2 \%$ were aware of the diagnosis, $10.2 \%$ were receiving treatment, and $3.8 \%$ had dyslipidemia controlled. The proportion of those aware of their condition and those who were treated increased with age in both sexes. Of those aware of their dyslipidemia, $46.1 \%$ were on treatment, $51.0 \%$ had modified their lifestyle, and $24.5 \%$ were not receiving treatment or modifying their lifestyle.

Conclusions: The major type of dyslipidemia in Beijing is high LDL-C rather than high TG. The prevalence of dyslipidemia is similarly high in rural and urban areas, with low awareness, treatment and control. A comprehensive strategy toward the prevention, screening, treatment, and control of dyslipidemia is needed to slow the epidemic of cardiovascular disease.

J Atheroscler Thromb, 2012; 19:159-168.

Key words; Dyslipidemias, Prevalence, Prevention and control, Risk factors

\section{Introduction}

Cardiovascular disease (CVD) is the leading cause of mortality worldwide, accounting for $30 \%$ of

Address for correspondence: Peiyu Wang, Department of Social Medicine and Health Education School of Public Health, Peking University Health Science Center, 38 Xueyuan Road, Haidian District, Beijing 100191, China

E-mail: peiyuwangpku@gmail.com

Received: May 15, 2011

Accepted for publication: August 16, 2011 all deaths ${ }^{1)}$. Most of this disease burden is in low- and middle-income countries. It has been estimated that annual CVD will increase by more than a half over the coming 20 years in China ${ }^{2)}$.

Dyslipidemia is one of the most important risk factors for $\mathrm{CVD}^{3)}$. The results from the Chinese $\mathrm{Na}$ tional Nutrition and Health Survey in 2002 (CNHS 2002) demonstrated that the prevalence of dyslipidemia in Chinese adults was $18.6 \%{ }^{4)}$. With the economic growth and associated lifestyle changes in China, the prevalence of dyslipidemia has increased signif- 
icantly during the last decade ${ }^{5-7)}$. Despite the growing prevalence of dyslipidemia, a previous study found that the awareness, treatment and control of dyslipidemia remained low in China ${ }^{8)}$.

Only a few recent studies have investigated the prevalence and risk factors of dyslipidemia in China, but none of these studies defined dyslipidemia according to the latest Chinese guidelines published in $2007^{9)}$. The cutoff values for high total cholesterol (TC), high low-density lipoprotein cholesterol (LDL-C) and low high-density lipoprotein cholesterol (HDL-C) are higher in the new than in the original guidelines. In addition, little is known about the awareness, treatment and control of dyslipidemia at present; therefore, the aims of the present study were (1) to identify levels of serum lipids among Beijing adults in 2008; (2) to estimate the major type of dyslipidemia, up-to-date prevalence and influence factors of dyslipidemia; and (3) to determine the awareness, treatment and control of dyslipidemia.

\section{Methods}

\section{Study Participants}

A cross-sectional study of CVD risk factors was conducted in Beijing in 2008. A four-stratified cluster sampling design was employed to select a representative sample of the general population aged 18 to 79 years. The first stage involved the random selection of 20 streets/townships. In the second stage, one residential committee/village and two organizations were randomly selected from each selected street/township. In the third stage, one group of approximately 100 households was randomly sampled from each selected residential committee/village and organization in stage two. In the fourth stage, one individual from each designated household was chosen. The probability proportional to size sampling method was adopted in the first three stages, and a Kish table was used in the final stage. Pregnant women were excluded from this study. Sixty groups in these 20 streets/townships were randomly selected. Finally, 6000 people aged 18 to 79 years were invited to participate in the study, 5899 participants completed the survey and examination, and 5761 (2398 men and 3363 women) were eligible for analysis.

Ethics approval was obtained from the Ethics Committee of Beijing Centers for Disease Control and Prevention. Written informed consent was acquired from each participant prior to enrollment.

\section{Data Collection \\ Questionnaire Interview}

Data were collected at physical examination centers at local health centers or community clinics in the participants' residential area. During the study visit, trained research staff administered a standardized questionnaire to obtain information on demographics, cigarette smoking, alcohol consumption, physical activity, medical history, and family history.

Total alcohol consumption (grams) per week was estimated by asking about the number of liang $(=50$ grams) of white spirits, beer, millet wine, and red wine they typically consumed in a week. Participants were also asked how many days (per week) and how much time (minutes per day) they normally participated in different types of physical activity. Metabolic equivalents (METS) of physical activity were calculated by multiplying the number of minutes spent participating in moderate sports activity by 4.0, vigorous sports activity by 8.0 , walking by 4.0 , moderate home activity by 3.5 , vigorous home activity by 7.0 , moderate farming by 3.0 and vigorous farming by $8.0^{10)}$.

\section{Anthropometric and Blood Pressure Measurement}

During the interview, weight, height and waist circumference were measured. Weight and height were measured in light indoor clothing without shoes using a standardized protocol. Body mass index (BMI) was calculated as weight divided by height squared $\left(\mathrm{kg} / \mathrm{m}^{2}\right)$. Waist circumference was measured halfway between the lowest rib margin and the iliac crest. Two consecutive readings of blood pressure (BP) were taken on the right arm using a calibrated mercury sphygmomanometer with the participant in a seated position and arm supported at heart level after at least 5 minutes of rest. If the difference in the two systolic or diastolic blood pressures recorded was greater than $4 \mathrm{mmHg}$, a third measurement was taken. The mean of these two measurements was applied in the subsequent analysis. The cuff size was chosen according to the upper arm circumference. Systolic blood pressure (SBP) was recorded at the first appearance of Korotkoff sounds and diastolic blood pressure (DBP) was recorded at the disappearance (phase V) of Korotkoff sounds.

\section{Laboratory Assay}

Twelve-hour fasting venous blood samples were collected in throwaway vacuum tubes and stored temporarily in an ice box. The blood samples were centrifuged at $3500 \times \mathrm{g}$ for 5 minutes at $4{ }^{\circ} \mathrm{C}$ within 2 hours and then refrigerated at $-80^{\circ} \mathrm{C}$ until analysis. All blood samples were analyzed within 5 days. Serum TC, LDL-C, HDL-C, triglycerides (TG) and glucose 
were measured using colorimetric methods with an Olympus AU2700 automated biochemistry analyzer (Olympus Optical Co., Tokyo, Japan) using commercial reagents (Wako Pure Chemical Industries, Ltd., Osaka, Japan). Reagents in the same batch were used to minimize laboratory variability. All procedures were conducted by trained technicians followed standardized protocols.

\section{Definitions}

Dyslipidemia was defined according to Chinese criteria $^{9)}$ : (1) TC $<5.18 \mathrm{mmol} / \mathrm{L}(200 \mathrm{mg} / \mathrm{dl})$ was considered as ideal, 5.18-6.21 mmol/L (200-239 mg/ $\mathrm{dl})$ as borderline high and $\geq 6.22 \mathrm{mmol} / \mathrm{L}(240 \mathrm{mg} /$ $\mathrm{dl})$ as high; LDL-C $<3.37 \mathrm{mmol} / \mathrm{L}(130 \mathrm{mg} / \mathrm{dl})$ was considered as ideal, $3.37-4.13 \mathrm{mmol} / \mathrm{L}(130-159 \mathrm{mg} /$ dl) as borderline high and $\geq 4.14 \mathrm{mmol} / \mathrm{L}(160 \mathrm{mg} /$ dl) as high; HDL-C $<1.04 \mathrm{mmol} / \mathrm{L}(40 \mathrm{mg} / \mathrm{dl})$ was considered as low and $\geq 1.04 \mathrm{mmol} / \mathrm{L}(40 \mathrm{mg} / \mathrm{dl})$ as ideal; TG $<1.70 \mathrm{mmol} / \mathrm{L}(150 \mathrm{mg} / \mathrm{dl})$ was considered as ideal, $1.10-2.25 \mathrm{mmol} / \mathrm{L}(150-199 \mathrm{mg} / \mathrm{dl})$ as borderline high and $\geq 2.26 \mathrm{mmol} / \mathrm{L}(200 \mathrm{mg} / \mathrm{dl})$ as high. Dyslipidemia was defined as high TC, and/or high LDL-C and/or low HDL-C, and/or high TG, and/or having received treatment for dyslipidemia in the previous 2 weeks. Participants who had been diagnosed with dyslipidemia were considered to be aware of their condition. Participants were considered to be treated if they answered "yes" to the interview question "Have you taken prescription medicine for dyslipidemia during the past 2 weeks?" Dyslipidemia was considered to be controlled in those receiving treatment if TC $<6.22$ $\mathrm{mmol} / \mathrm{L}$, LDL-C $<4.14 \mathrm{mmol} / \mathrm{L}$, HDL-C $\geq 1.04$ $\mathrm{mmol} / \mathrm{L}$, and $\mathrm{TG}<2.26 \mathrm{mmol} / \mathrm{L}$.

Hypertension was defined as mean $\mathrm{SBP} \geq 140$ $\mathrm{mmHg}$ and/or mean DBP $\geq 90 \mathrm{mmHg}$, and/or selfreported antihypertensive treatment in the previous 2 weeks. Diabetes was defined as fasting blood glucose $(F B G) \geq 7.0 \mathrm{mmol} / \mathrm{L}(126 \mathrm{mg} / \mathrm{dL})$, and/or self-reported pharmacological treatment for diabetes during the previous 2 weeks.

Those who reported having smoked $\geq 100$ cigarettes in the past were defined as current smokers if they had smoked in the last 30 days, or past smokers if they had exhibited complete abstinence from cigarette use for at least one month ${ }^{11}$. Drinking categories, classified according to the American National Institute on Alcohol Abuse and Alcoholism, were as follows: never drinkers (had never drunk alcohol), light drinkers ( $<7$ drinks/week for men and $<4$ drinks/ week for women), moderate drinkers (7-14 drinks/ week for men and 4-7 drinks/week for women), and at-risk drinkers $(>14$ drinks/week for men and $>7$ drinks/week for women). Participants were grouped into low, moderate and high physical activity categories according to the Global Physical Activity Questionnaire Analysis Guide ${ }^{12)}$.

Body size was graded according to the Chinese specific criteria ${ }^{13)}$ for defining underweight (BMI < 18.5), normal weight (BMI 18.5-23.9), overweight (BMI 24-27.9), and obesity (BMI $\geq 28$ ). Waist circumference was categorized into three groups ${ }^{13)}$ : low $(<85 \mathrm{~cm}$ for men and $<80 \mathrm{~cm}$ for women), intermediate $(85-95 \mathrm{~cm}$ for men and $80-90 \mathrm{~cm}$ for women) and high $(>95 \mathrm{~cm}$ for men and $>90 \mathrm{~cm}$ for women, as a marker of central obesity).

\section{Statistical Analysis}

Mean levels of age, BMI, waist circumference, BP, serum lipids and FBG were determined by sex. The percentage distribution of TC, LDL-C, HDL-C and TG was calculated for the overall population and by sex, age and residential area. Trend $\chi^{2}$ and $\chi^{2}$ tests were performed to test differences in proportions by age and residential area, respectively. Crude differences among the prevalence of dyslipidemia across participant characteristics (e.g., men versus women) were determined using $\chi^{2}$ test. The adjusted odds ratios (ORs) and 95\% confidence intervals (CI) of dyslipidemia prevalence with different participant characteristics were determined using a multivariate logistic regression model. In the multivariate model, independent variables included sex, age group, residential area, family history of dyslipidemia, education level, smoking, drinking, physical activity, BMI, waist circumference, hypertension and diabetes.

The awareness, treatment and control of dyslipidemia were calculated by sex, age, and residential area. For these analyses, awareness was restricted to participants with dyslipidemia, treatment to those aware of their diagnosis, and control to those who were being treated. The proportion of participants who were modifying their lifestyle to control their serum lipids among those aware of their dyslipidemia diagnosis was also calculated. All statistical analyses were conducted using Statistical Analysis Systems Software (version 9.1; SAS Institute, Cary, NC). Twotailed $P<0.05$ was considered significant.

\section{Results}

\section{Characteristics of Study Participants}

General characteristics of the study participants are shown in Table 1. The mean TC, LDL-C and HDL-C were slightly higher in urban than in rural areas in women. Mean LDL-C and TG were lower in 
Table 1. General characteristics of the study participants (mean \pm SD)

\begin{tabular}{|c|c|c|c|c|c|}
\hline \multirow[t]{2}{*}{ Characteristics } & \multicolumn{2}{|c|}{$\begin{array}{c}\text { Men } \\
(n=2398)\end{array}$} & \multicolumn{2}{|c|}{$\begin{array}{l}\text { Women } \\
(n=3363)\end{array}$} & \multirow{2}{*}{$\begin{array}{c}\text { Total } \\
(n=5761)\end{array}$} \\
\hline & Rural & Urban & Rural & Urban & \\
\hline Age (years) & $42.74 \pm 13.48$ & $44.17 \pm 15.81^{*}$ & $42.58 \pm 13.30$ & $45.99 \pm 13.77^{* *}$ & $43.88 \pm 13.97$ \\
\hline BMI $\left(\mathrm{kg} / \mathrm{m}^{2}\right)$ & $25.68 \pm 3.61$ & $25.10 \pm 3.56^{*}$ & $24.64 \pm 3.84$ & $24.38 \pm 3.68^{*}$ & $24.91 \pm 3.76$ \\
\hline Waist circumference $(\mathrm{cm})$ & $87.95 \pm 10.02$ & $87.78 \pm 9.97$ & $79.15 \pm 9.99$ & $79.92 \pm 9.29 *$ & $83.03 \pm 10.61$ \\
\hline SBP (mmHg) & $134.3 \pm 17.9$ & $133.3 \pm 18.6$ & $126.4 \pm 18.7$ & $125.6 \pm 19.1$ & $129.4 \pm 19.2$ \\
\hline $\mathrm{DBP}(\mathrm{mmHg})$ & $84.0 \pm 10.4$ & $83.7 \pm 11.2$ & $80.1 \pm 10.0$ & $79.5 \pm 10.4$ & $81.5 \pm 10.7$ \\
\hline TC (mmol/L) & $5.09 \pm 1.09$ & $5.00 \pm 0.98$ & $4.96 \pm 0.99$ & $5.14 \pm 1.04^{*}$ & $5.05 \pm 1.03$ \\
\hline LDL-C (mmol/L) & $3.37 \pm 1.11$ & $3.23 \pm 0.95^{*}$ & $3.14 \pm 0.96$ & $3.32 \pm 1.00^{* *}$ & $3.27 \pm 1.01$ \\
\hline HDL-C (mmol/L) & $1.37 \pm 0.48$ & $1.37 \pm 0.40$ & $1.57 \pm 0.41$ & $1.60 \pm 0.48^{*}$ & $1.50 \pm 0.47$ \\
\hline TG (mmol/L) & $1.89 \pm 2.37$ & $1.69 \pm 1.51^{*}$ & $1.32 \pm 1.29$ & $1.35 \pm 1.09$ & $1.53 \pm 1.62$ \\
\hline $\mathrm{FBG}(\mathrm{mmol} / \mathrm{L})$ & $5.30 \pm 1.77$ & $5.30 \pm 1.42$ & $5.02 \pm 1.39$ & $5.11 \pm 1.33$ & $5.15 \pm 1.47$ \\
\hline \multicolumn{6}{|l|}{ Smoking status (\%) } \\
\hline Never & 36.30 & 40.31 & 96.88 & $95.56^{*}$ & 71.88 \\
\hline Current & 58.70 & $50.79 * *$ & 2.63 & 3.64 & 25.00 \\
\hline Past & 5.00 & $8.90^{* *}$ & 0.49 & 0.80 & 3.13 \\
\hline \multicolumn{6}{|l|}{ Drinking status (\%) } \\
\hline Never & 31.56 & 33.95 & 81.75 & $76.74^{* *}$ & 60.41 \\
\hline Light & 57.79 & 58.22 & 17.76 & $22.45^{* *}$ & 35.14 \\
\hline Moderate & 5.56 & 4.13 & 0.12 & $0.63^{*}$ & 2.40 \\
\hline At risk & 5.09 & 3.70 & 0.37 & 0.19 & 2.05 \\
\hline Hypertension (\%) & 42.57 & 40.31 & 28.67 & $32.80^{*}$ & 35.46 \\
\hline Diabetes (\%) & 9.56 & 10.16 & 5.68 & $7.64^{*}$ & 7.85 \\
\hline $\operatorname{CVD}(\%)^{\dagger}$ & 1.72 & 2.83 & 0.73 & $1.48^{*}$ & 1.56 \\
\hline
\end{tabular}

${ }^{*} P<0.05$ vs. rural. ${ }^{* *} P<0.001$ vs. rural. ${ }^{\dagger}$ Prevalence of self-reported CVD.

SD, standard deviation; BMI, body mass index; SBP, systolic blood pressure; DBP, diastolic blood pressure; TC, total cholesterol; LDL-C, low-density lipoprotein cholesterol; HDL-C, high-density lipoprotein cholesterol; TG, triglycerides; FBG, fasting blood glucose; CVD, cardiovascular diseases.

urban areas in men than in rural areas. The prevalence of hypertension, diabetes and CVD was higher in urban than in rural areas in women.

\section{Distribution of Serum Lipids}

The distribution of serum lipids by sex, age and residential area is shown in Table 2 . The prevalence of borderline high and high TC was $29.0 \%$ and $12.2 \%$, respectively. The proportion of those who had a desirable TC concentration decreased with age in both sexes. The prevalence of borderline high and high TC was higher in urban than in rural areas in women. The prevalence of borderline high and high LDL-C was $24.2 \%$ and $17.9 \%$, respectively. The prevalence of high LDL-C increased with age, and was higher in men $<50$ years and lower in men $\geq 50$ years than in women. The prevalence of borderline high and high LDL-C in men was lower in urban than in rural areas, and a reverse result was found in women. The overall prevalence of low HDL-C was $12.0 \%$. The prevalence of low HDL-C increased with age before 60 years but decreased thereafter in both sexes. The prevalence of borderline high and high TG was $12.3 \%$ and $15.1 \%$, respectively. The prevalence for both was higher in men than in women. The prevalence of high TG increased by age until approximately age 50 in men and 60 in women, and then began to decline. The areaspecific prevalence of high TG and low HDL-C did not differ in both sexes.

\section{Prevalence and Influencing Factors of Dyslipidemia}

The overall prevalence of dyslipidemia was $35.4 \%$ in the general adult population. After excluding participants with CVD or familial hypercholesterolemia $(n=100)$, the prevalence of dyslipidemia was $34.4 \%$. The dyslipidemia prevalence was higher in men than in women, and increased with age (Table 3 ). There was no difference in dyslipidemia prevalence 
Table 2. Percentage distribution of serum lipids by sex, age and residential area

\begin{tabular}{|c|c|c|c|c|c|c|c|c|}
\hline \multirow[b]{3}{*}{$\mathrm{TC}\left(\mathrm{mmol} / \mathrm{L}^{\S}\right)$} & \multicolumn{4}{|c|}{ Men } & \multicolumn{4}{|c|}{ Women } \\
\hline & \multicolumn{3}{|c|}{ Percentage (\%) } & \multirow[t]{2}{*}{$P$} & \multicolumn{3}{|c|}{ Percentage (\%) } & \multirow[t]{2}{*}{$P$} \\
\hline & $<5.18$ & $5.18-6.21$ & $\geq 6.22$ & & $<5.18$ & $5.18-6.21$ & $\geq 6.22$ & \\
\hline Total & 57.3 & 30.6 & 12.1 & & 59.9 & 27.8 & 12.3 & $0.069 *$ \\
\hline Age & & & & $<0.001^{\dagger}$ & & & & $<0.001^{\dagger}$ \\
\hline $18-29$ & 78.1 & 16.8 & 5.1 & & 83.6 & 12.8 & 3.6 & \\
\hline $30-39$ & 60.1 & 30.8 & 9.1 & & 76.5 & 18.3 & 5.2 & \\
\hline $40-49$ & 49.3 & 32.7 & 18.1 & & 60.7 & 30.0 & 9.3 & \\
\hline $50-59$ & 50.0 & 36.7 & 13.4 & & 37.7 & 41.6 & 20.7 & \\
\hline $60-79$ & 47.5 & 39.7 & 12.9 & & 34.5 & 37.5 & 28.0 & \\
\hline Residential area & & & & $0.376^{\text {末 }}$ & & & & $<0.001^{\ddagger}$ \\
\hline Rural & 56.3 & 31.5 & 12.2 & & 64.1 & 25.5 & 10.4 & \\
\hline Urban & 59.2 & 29.9 & 11.0 & & 55.5 & 30.5 & 14.0 & \\
\hline LDL-C (mmol/L) & $<3.37$ & $3.37-4.13$ & $\geq 4.14$ & & $<3.37$ & $3.37-4.13$ & $\geq 4.14$ & \\
\hline Total & 54.0 & 27.4 & 18.6 & & 60.5 & 22.0 & 17.5 & $<0.001^{*}$ \\
\hline Age & & & & $<0.001^{\dagger}$ & & & & $<0.001^{\dagger}$ \\
\hline $18-29$ & 75.2 & 16.1 & 8.7 & & 84.6 & 9.4 & 6.0 & \\
\hline $30-39$ & 54.9 & 29.1 & 16.1 & & 76.2 & 16.4 & 7.4 & \\
\hline $40-49$ & 48.3 & 28.5 & 23.2 & & 60.6 & 25.3 & 14.2 & \\
\hline $50-59$ & 44.6 & 34.1 & 21.3 & & 39.3 & 31.7 & 29.1 & \\
\hline $60-79$ & 43.7 & 31.2 & 25.1 & & 36.9 & 25.9 & 37.3 & \\
\hline Residential area & & & & $0.007^{\text {米 }}$ & & & & $<0.001^{\ddagger}$ \\
\hline Rural & 51.4 & 29.5 & 19.1 & & 64.8 & 20.5 & 14.8 & \\
\hline Urban & 58.0 & 25.0 & 17.1 & & 56.2 & 23.7 & 20.1 & \\
\hline HDL-C (mmol/L) & $\geq 1.04$ & & $<1.04$ & & $\geq 1.04$ & & $<1.04$ & \\
\hline Total & 80.5 & & 19.5 & & 93.3 & & 6.7 & $<0.001^{*}$ \\
\hline Age & & & & $<0.001^{\dagger}$ & & & & $<0.001^{\dagger}$ \\
\hline $18-29$ & 85.7 & & 3.1 & & 95.8 & & 4.2 & \\
\hline $30-39$ & 78.5 & & 21.5 & & 94.3 & & 5.7 & \\
\hline $40-49$ & 77.7 & & 22.3 & & 93.9 & & 6.2 & \\
\hline $50-59$ & 77.6 & & 22.4 & & 90.3 & & 9.7 & \\
\hline $60-79$ & 84.8 & & 15.3 & & 92.0 & & 8.0 & \\
\hline Residential area & & & & $0.691^{\text {事 }}$ & & & & $0.681^{\text {* }}$ \\
\hline Rural & 80.0 & & 20.1 & & 93.0 & & 7.0 & \\
\hline Urban & 80.6 & & 19.4 & & 93.4 & & 6.6 & \\
\hline $\mathrm{TG}(\mathrm{mmol} / \mathrm{L})$ & $<1.70$ & $1.70-2.25$ & $\geq 2.26$ & & $<1.70$ & $1.70-2.25$ & $\geq 2.26$ & \\
\hline Total & 64.4 & 15.0 & 20.6 & & 78.3 & 10.5 & 11.3 & $<0.001^{*}$ \\
\hline Age & & & & $<0.001^{\dagger}$ & & & & $<0.001^{\dagger}$ \\
\hline $18-29$ & 77.9 & 9.9 & 12.2 & & 93.7 & 3.1 & 3.2 & \\
\hline $30-39$ & 63.6 & 14.9 & 21.5 & & 88.2 & 5.7 & 6.1 & \\
\hline $40-49$ & 54.0 & 16.4 & 29.6 & & 79.9 & 10.4 & 9.7 & \\
\hline $50-59$ & 61.7 & 16.7 & 21.6 & & 63.4 & 16.1 & 20.5 & \\
\hline $60-79$ & 70.5 & 17.3 & 12.2 & & 61.6 & 19.2 & 19.2 & \\
\hline Residential area & & & & $0.110^{\text {क }}$ & & & & $0.409^{\text {क }}$ \\
\hline Rural & 62.5 & 15.5 & 22.0 & & 79.1 & 9.8 & 11.1 & \\
\hline Urban & 66.7 & 13.8 & 19.5 & & 77.4 & 11.2 & 11.4 & \\
\hline
\end{tabular}

${ }^{*} P$ value for difference between men and women. ${ }^{\dagger} P$ for trend across age groups. ${ }^{*} P$ value for difference between rural and urban areas.

${ }^{\S}$ Conversion of lipid profile units is as follows: TC, $5.18 \mathrm{mmol} / \mathrm{L}=200 \mathrm{mg} / \mathrm{dL}, 6.22 \mathrm{mmol} / \mathrm{L}=240 \mathrm{mg} / \mathrm{dL} ; \mathrm{LDL}-\mathrm{C}, 3.37 \mathrm{mmol} / \mathrm{L}=130 \mathrm{mg} / \mathrm{dL}, 4.14$ $\mathrm{mmol} / \mathrm{L}=160 \mathrm{mg} / \mathrm{dL} ; \mathrm{HDL}-\mathrm{C}, 1.04 \mathrm{mmol} / \mathrm{L}=40 \mathrm{mg} / \mathrm{dL} ; \mathrm{TG}, 1.70 \mathrm{mmol} / \mathrm{L}=150 \mathrm{mg} / \mathrm{dL}, 2.26 \mathrm{mmol} / \mathrm{L}=200 \mathrm{mg} / \mathrm{dL}$.

TC, total cholesterol; LDL-C, low-density lipoprotein cholesterol; HDL-C, high-density lipoprotein cholesterol; TG, triglycerides. 
Table 3. Prevalence of dyslipidemia by selected characteristics and adjusted odds ratio (95\% CI) of dyslipidemia prevalence

\begin{tabular}{|c|c|c|c|c|c|}
\hline & $n^{\dagger}$ & Prevalence (\%) & $P$ & Adjusted OR $(95 \% \mathrm{CI})$ & $P^{*}$ \\
\hline Sex & & & $<0.001^{\text {* }}$ & & \\
\hline Female & 3363 & 30.1 & & 1.00 & \\
\hline Male & 2398 & 42.9 & & $1.40(1.17,1.68)$ & $<0.001$ \\
\hline Age & & & $<0.001^{\S}$ & & \\
\hline $18-29$ & 1037 & 19.1 & & 1.00 & \\
\hline $30-39$ & 1246 & 25.4 & & $1.42(1.12,1.79)$ & 0.004 \\
\hline $40-49$ & 1574 & 37.2 & & $1.88(1.50,2.35)$ & $<0.001$ \\
\hline $50-59$ & 1136 & 48.1 & & $2.73(2.14,3.47)$ & $<0.001$ \\
\hline $60-79$ & 765 & 51.5 & & $2.79(2.13,3.66)$ & $<0.001$ \\
\hline Residential area & & & $0.688^{\ddagger}$ & & \\
\hline Rural & 2975 & 35.3 & & 1.00 & \\
\hline Urban & 2577 & 35.8 & & $0.97(0.85,1.11)$ & 0.628 \\
\hline Family history & & & $<0.001^{*}$ & & \\
\hline No & 4919 & 34.3 & & 1.00 & \\
\hline yes & 536 & 45.5 & & $1.85(1.50,2.28)$ & $<0.001$ \\
\hline Education & & & $<0.001^{\S}$ & & \\
\hline$<$ High school & 2066 & 38.6 & & 1.00 & \\
\hline High school & 1478 & 35.9 & & $1.09(0.92,1.29)$ & 0.328 \\
\hline College or above & 2153 & 32.1 & & $1.19(1.01,1.41)$ & 0.042 \\
\hline Smoking status & & & $<0.001^{\ddagger}$ & & \\
\hline Never & 4140 & 31.5 & & 1.00 & \\
\hline Current & 1440 & 44.9 & & $1.38(1.13,1.67)$ & 0.001 \\
\hline Past & 180 & 50.0 & & $1.21(0.84,1.73)$ & 0.308 \\
\hline Drinking status & & & $0.001^{\S}$ & & \\
\hline Never & 3392 & 34.1 & & 1.00 & \\
\hline Light & 1973 & 36.4 & & $0.94(0.80,1.11)$ & 0.471 \\
\hline Moderate & 135 & 44.4 & & $0.82(0.53,1.26)$ & 0.357 \\
\hline At risk & 115 & 47.8 & & $0.90(0.58,1.40)$ & 0.638 \\
\hline Physical activity & & & $0.002^{\S}$ & & \\
\hline Low & 828 & 34.5 & & 1.00 & \\
\hline Moderate & 2594 & 33.3 & & $0.92(0.76,1.12)$ & 0.399 \\
\hline High & 2150 & 38.8 & & $0.94(0.76,1.15)$ & 0.530 \\
\hline BMI & & & $<0.001^{\S}$ & & \\
\hline$<18.5$ & 131 & 16.0 & & $1.02(0.60,1.73)$ & 0.956 \\
\hline$\leq 18.5-24$ & 2347 & 20.6 & & 1.00 & \\
\hline$\leq 24-28$ & 2155 & 43.7 & & $1.70(1.44,2.02)$ & $<0.001$ \\
\hline$\geq 28$ & 1099 & 54.1 & & $1.96(1.55,2.48)$ & $<0.001$ \\
\hline Waist circumference & & & $<0.001^{\S}$ & & \\
\hline Low & 2633 & 20.4 & & 1.00 & \\
\hline Intermediate & 1966 & 43.8 & & $1.70(1.44,2.02)$ & $<0.001$ \\
\hline High & 1130 & 56.6 & & $1.96(1.55,2.48)$ & $<0.001$ \\
\hline Hypertension & & & $<0.001^{*}$ & & \\
\hline No & 3718 & 27.5 & & 1.00 & \\
\hline Yes & 2043 & 49.7 & & $1.31(1.14,1.52)$ & $<0.001$ \\
\hline Diabetes & & & $<0.001^{\text {* }}$ & & \\
\hline No & 5309 & 33.3 & & 1.00 & \\
\hline Yes & 452 & 60.0 & & $1.74(1.39,2.19)$ & $<0.001$ \\
\hline
\end{tabular}

* Odds ratio for each variable is adjusted for all other variables shown. ${ }^{\dagger}$ Number of participants, including those with or without dyslipidemia. ${ }^{\ddagger} P$ values: female vs. male, rural vs. urban, no vs. yes (family history), never vs. current and past smokers, hypertensives vs. non-hypertensives, diabetics vs. non-diabetics. ${ }^{\S} P$ for trend across age groups, educational levels, drinking status, physical activity levels, BMI categories, and waist circumference categories, respectively. OR, odds ratio; CI, confidence intervals; BMI, body mass index; family history, family history of dyslipidemia. 
Table 4. Dyslipidemia awareness, treatment and control by sex, age and residential areas

\begin{tabular}{|c|c|c|c|c|c|c|}
\hline & \multicolumn{2}{|c|}{ Awareness $^{\dagger}$} & \multicolumn{2}{|c|}{ treatment } & \multicolumn{2}{|c|}{ Control $^{\dagger \dagger}$} \\
\hline & $\begin{array}{l}\text { Men } \\
n(\%)\end{array}$ & $\begin{array}{l}\text { Women } \\
n(\%)\end{array}$ & $\begin{array}{l}\text { Men } \\
n(\%)\end{array}$ & $\begin{array}{l}\text { Women } \\
n(\%)\end{array}$ & $\begin{array}{l}\text { Men } \\
n(\%)\end{array}$ & $\begin{array}{l}\text { Women } \\
n(\%)\end{array}$ \\
\hline Total & $212(20.7)$ & 238 (23.6) & 99 (46.7) & $108(45.6)$ & $29(29.6)$ & $49(45.4)^{*}$ \\
\hline \multicolumn{7}{|l|}{ Age } \\
\hline $18-29$ & $10(7.4)$ & $3(4.9)$ & $1(10.0)$ & $2(66.7)$ & $0(0.0)$ & $2(100.0)$ \\
\hline $30-39$ & $23(12.8)$ & $24(17.8)$ & $6(26.1)$ & $6(25.0)$ & $2(33.3)$ & $3(50.0)$ \\
\hline $40-49$ & $80(22.7)$ & $55(23.7)$ & $35(43.8)$ & $18(33.3)$ & $5(14.3)$ & $11(61.1)$ \\
\hline $50-59$ & $61(26.8)$ & $90(28.5)$ & $29(47.5)$ & $40(44.4)$ & $10(34.5)$ & $13(32.5)$ \\
\hline $60-79$ & $38(29.2)$ & $66(25.1)$ & $28(73.7)$ & $42(63.6)$ & $12(44.4)$ & $20(47.6)$ \\
\hline$P$ for trend & $<0.001$ & $<0.001$ & $<0.001$ & $<0.001$ & 0.024 & 0.257 \\
\hline \multicolumn{7}{|l|}{ Residential area } \\
\hline Rural & $115(19.6)$ & $85(18.6)$ & 54 (46.9) & $39(45.9)$ & $18(33.3)$ & $18(46.2)$ \\
\hline Urban & $90(22.7)$ & $151(28.9)$ & $43(47.8)$ & $68(45.3)$ & $11(26.2)$ & $30(44.12)$ \\
\hline$P$ value & 0.235 & $<0.001$ & 0.907 & 0.935 & 0.452 & 0.839 \\
\hline
\end{tabular}

Table 5. Percentage of participants adopted lifestyle modifications among those aware of their dyslipidemia by pharmacological treatment

\begin{tabular}{lccc}
\hline Lifestyle & \multicolumn{3}{c}{$n(\%)$} \\
\cline { 2 - 4 } modifications & Treated & Untreated & Total \\
\hline Any of the following & $97(46.9)$ & $132(54.6)$ & $229(51.0)$ \\
$\quad$ Diet control & $77(37.2)$ & $102(42.2)$ & $179(39.9)$ \\
Exercise & $80(38.7)$ & $88(36.4)$ & $168(37.4)$ \\
Others & $1(0.5)$ & $8(3.3)^{*}$ & $9(2.0)$ \\
\hline
\end{tabular}

${ }_{p} p<0.05$ compared with the treated group.

between rural and urban areas. A higher prevalence of dyslipidemia was found among those who had a family history of dyslipidemia, lower educational attainment, were current/past smokers, drinkers, had high physical activity, were overweight and obese, or had a larger waist circumference, hypertensive or diabetes (all $P<0.01)$. Results of multiple logistic regression analysis revealed that the presence of dyslipidemia was significant associated with male gender, age ( $\geq 30$ years), a family history of dyslipidemia, education at college or above, being a current smoker, overweight and obesity, and having an intermediate or high waist circumference, hypertension and diabetes. Risk factors for high LDL-C identified by the multiple regression model were as follow: female gender, age ( $\geq 40$ years), education at college or above, being a current smoker, overweight, having intermediate or high waist circumference, hypertension and diabetes (data not shown).
Awareness, Treatment and Control of Dyslipidemia Among all participants with dyslipidemia, 22.2\% (20.7\% in men and $23.6 \%$ in women) were aware of the diagnosis, $10.2 \%$ (9.6\% in men and $10.8 \%$ in women) were receiving treatment, and $3.8 \%(2.8 \%$ in men and $4.9 \%$ in women) had their dyslipidemia under control. Awareness increased with age in both men and women (Table 4). Women in rural areas (18.6\%) were less aware than women in urban areas $(28.9 \%)$. Of 450 participants aware of their dyslipidemia, $46.1 \%$ (46.7\% in men and $45.6 \%$ in women) reported using drugs for dyslipidemia. The proportion of treated individuals increased with age. Of those who were receiving treatment, the percentage of participants with controlled dyslipidemia was 37.8\% (29.6\% in men and $45.4 \%$ in women). The percentage of controlled dyslipidemia increased with age in men but not in women. The percentage of treated and controlled dyslipidemia was similar in rural and urban areas in both sexes, respectively.

Of those aware of their dyslipidemia diagnosis, $51.0 \%$ had modified their lifestyle (Table 5), such as diet control (39.9\%) and exercise (37.4\%). Overall, $24.5 \%$ of those aware of their dyslipidemia were not receiving treatment or modifying their lifestyle.

\section{Discussion}

Our results highlight three important conclusions. First, the major type of dyslipidemia in Beijing is high LDL-C rather than high TG or low HDL-C. The prevalence of borderline high and high LDL-C 
was $24.2 \%$ and $17.9 \%$, respectively. Second, the prevalence of dyslipidemia is high in the general adult population aged $18-79$ years in Beijing, as $35.4 \%$ of participants had at least one type of dyslipidemia. Third, control of dyslipidemia is poor. In those with dyslipidemia, $22.2 \%$ were aware of their dyslipidemia, $10.2 \%$ were receiving treatment, and $3.8 \%$ had their serum lipids under control. Even in those who reported that they were taking treatment for dyslipidemia, only $37.8 \%$ had their serum lipids controlled.

The mean serum TC, LDL-C and TG in China have increased rapidly in the last decade ${ }^{4,14,15)}$. Findings from CNHS $2002^{4,9)}$ showed that the mean levels of TC, LDL-C and TG were $3.81 \mathrm{mmol} / \mathrm{L} \mathrm{(147.1}$ $\mathrm{mg} / \mathrm{dL}), 2.12 \mathrm{mmol} / \mathrm{L}(81.9 \mathrm{mg} / \mathrm{dL})$ and 1.10 $\mathrm{mmol} / \mathrm{L}(97.3 \mathrm{mg} / \mathrm{dL})$, respectively, which were relatively low; however, the corresponding mean levels observed in the current study were $5.05 \mathrm{mmol} / \mathrm{L}(195.0$ $\mathrm{mg} / \mathrm{dL}), 3.27 \mathrm{mmol} / \mathrm{L}(126.3 \mathrm{mg} / \mathrm{dL})$ and 1.53 $\mathrm{mmol} / \mathrm{L}(135.4 \mathrm{mg} / \mathrm{dL})$, respectively, which suggested that the mean serum TC, LDL-C and TG in Beijing is coming close to those in developed countries, such as Australasia, North America, and western Europe ${ }^{16,17)}$. Notably, the mean level of serum HDL-C also increased slightly.

With the substantial increase in the mean level of serum TC and LDL-C, the major types of dyslipidemia in Beijing have changed. Previous studies demonstrated that the major types of dyslipidemia in China are high TG and low HDL-C ${ }^{6,8,18)}$; however, the results of our study showed that less than $60 \%$ of participants had their TC or LDL-C concentration in the desirable range. On the other hand, more than $70 \%$ of participants had achieved the ideal serum TG. The prevalence of high TC, high LDL-C, low HDL-C and high TG was $12.2 \%, 17.9 \%, 12.0 \%$ and $15.1 \%$, respectively. In view of the above points, it is clear that the major types of dyslipidemia in Beijing are high TC and high LDL-C, similar to western countries ${ }^{16}$. Beijing, as one of the most urbanized cities in China, has experienced rapid urbanization and marked economic growth, which are accompanied by detrimental changes in diet and lifestyle. The change in dyslipidemia types may be the consequence of economic development, urbanization, and nutritional transition. This new finding should be of great concern, and more studies in China should be conducted to assess the dyslipidemia types in different regions and to evaluate the association between dyslipidemia and lifestyle and dietary patterns.

A few regional studies have examined the prevalence of dyslipidemia in Chinese populations recent$1 y^{5,14,15)}$, but none of these studies reported the dyslip- idemia prevalence according to the latest Chinese criteria ${ }^{9)}$. Based on the new criteria in China, we report here the prevalence of dyslipidemia among adults in Beijing using data obtained in 2008. Overall, 35.4\% of participants had dyslipidemia (including high TC, high LDL-C, low HDL-C, high TG, or self-reported current use of anti-dyslipidemia medications). Our findings, together with other studies ${ }^{5,18,19)}$, confirmed that the prevalence of dyslipidemia is increasing in China. For example, in a cross-sectional study among 6412 rural hypertensives aged $\geq 35$ years, $37.2 \%$ had dyslipidemia ${ }^{5)}$. It is apparent that China is going to experience a large increase in the prevalence of cardiovascular-related morbidity and mortality, which will bring an enormous future burden on the health care system.

Several well-established risk factors for dyslipidemia $^{18,20-23)}$, including age, family history of dyslipidemia, current smoking, overweight and obesity, were clearly associated with dyslipidemia in the present study. The increased prevalence of dyslipidemia may be partially attributed to an increase in the prevalence of overweight and obesity. In 2002, approximately $30 \%$ of adult city dwellers in China were affected by overweight or obesity ${ }^{18)}$, whereas the corresponding proportion in our study was $56.8 \%$. Age also contributes to the increased prevalence of dyslipidemia. In our study, the prevalence of dyslipidemia increased from $19.1 \%$ in the $18-29$ year age group to $51.5 \%$ in the 60-79 year age group. With the aging population trend in China, the picture of the public health burden posed by dyslipidemia will be aggravated. Our results also indicated that male gender and education at college or above were related to dyslipidemia. Our data highlight the relationships among hypertension, diabetes and dyslipidemia; $49.7 \%$ of hypertensives and $60.0 \%$ of diabetics had dyslipidemia. The presence of hypertension or diabetes led to a higher odds ratio for dyslipidemia even after adjusting for other relative variables $(\mathrm{OR}=1.31$ and $\mathrm{OR}=1.74$, respectively). More attention should be paid to those with an additional comorbid condition, given that dyslipidemia, hypertension and diabetes are established risk factors for CVD morbidity and mortality ${ }^{3)}$.

It is noteworthy that we observed a similar prevalence of dyslipidemia in rural (35.3\%) and urban $(35.8 \%)$ areas in Beijing. In previous Chinese surveys, there was a great disparity in the prevalence of dyslipidemia between rural and urban areas ${ }^{8,18)}$. It is suggested that the growth in the prevalence of dyslipidemia is faster in rural than in urban areas. If this trend continues, the prevalence of dyslipidemia in Beijing might be greater in rural than urban areas in the next 
few years.

It was reported by InterASIA that the proportion of individuals aware, treated, and with controlled serum lipids among participants with dyslipidemia was unacceptably low in the Chinese population ${ }^{8)}$. Similar disappointing results were also found in our study, as only $3.8 \%$ of those with dyslipidemia had their serum lipids controlled. The poor control of dyslipidemia can be explained in part by a lack of awareness and treatment. Nearly four-fifths of participants with dyslipidemia were unaware of their condition. Despite the growing evidence of the benefit of controlling serum lipids ${ }^{24)}$, poor compliance with recommended medication use for lipid control was seen in our study. More than $50 \%$ of those who were aware of their diagnosis failed to receive treatment. The proportion of awareness and treatment increased with age, which was consistent with studies in America ${ }^{25,26)}$. Older adults may have increased screening and are more likely to be on medication ${ }^{27)}$ because they are more likely to have dyslipidemia than younger adults. It should be noted that the awareness in young people was extremely low. Our findings underscore the need for efforts to identify adults with dyslipidemia through increased screening, and to improve the treatment rate.

However, medication alone will not solve the problem of dyslipidemia control completely. In the current study, even in those who were receiving treatment for dyslipidemia, only $29.6 \%$ men and $45.4 \%$ women had their serum lipids controlled. Other intervention and observed studies have shown that lifestyle changes are effective in controlling serum lipids ${ }^{26,28,29)}$. Furthermore, the combination of medication and lifestyle changes is more effective in controlling serum lipids than medication or lifestyle changes alone. In our study, among those aware of their dyslipidemia, only $46.1 \%$ were taking medication, $51.0 \%$ were practicing one or more lifestyle changes, and $24.5 \%$ were following no medical recommendations (no lifestyle changes and not taking anti-dyslipidemia medication). Specific interventions to improve adherence to medical recommendations should be implemented, such as using financial and regulatory mechanisms to encourage a healthy diets ${ }^{30)}$, and creating a friendly environment for physical activity to promote physical exercise $^{31)}$.

The findings of the present analysis should be interpreted with an understanding of the following potential limitations. Potential sources of bias include recall bias of self-reported information, and possible serum lipid control by non-pharmacological means, such as diet or/and exercise. The Chinese criteria were adopted to define dyslipidemia; therefore, it is not straighforward for us to compare our results with those in other countries directly. Finally, this was a cross-sectional study, thus no causal relationships could be precisely delineated.

In conclusion, our study provides reliable and up-to-date information on dyslipidemia in the adult population in Beijing. The major type of dyslipidemia was high LDL-C rather than high TG. The prevalence of dyslipidemia was high in both rural and urban areas, with unacceptable low awareness, treatment and control. Our results suggest that renewed efforts are needed to lower the prevalence of dyslipidemia and to raise the proportion of controlled dyslipidemia. These efforts should include aggressive promotion of a healthy lifestyle, and a comprehensive strategy toward screening, treatment, and control of dyslipidemia.

\section{References}

1) Mehra R: Global public health problem of sudden cardiac death. J Electrocardiol, 2007; 40: S118-S122

2) Moran A, Gu D, Zhao D, Coxson P, Wang YC, Chen CS, Liu J, Cheng J, Bibbins-Domingo K, Shen YM, He J, Goldman L: Future cardiovascular disease in china: markov model and risk factor scenario projections from the coronary heart disease policy model-china. Circ Cardiovasc Qual Outcomes, 2010; 3: 243-252

3) Yusuf S, Reddy S, Ounpuu S, Anand S: Global burden of cardiovascular diseases: part I: general considerations, the epidemiologic transition, risk factors, and impact of urbanization. Circulation, 2001; 104: 2746-2753

4) Zhao WH, Zhang J, Zhai Y, You Y, Man QQ, Wang CR, Li H, Li Y, Yang XG: Blood lipid profile and prevalence of dyslipidemia in Chinese adults. Biomed Environ Sci, 2007; 20: 329-335

5) Zhang X, Sun Z, Zheng L, Li J, Liu S, Xu C, Li J, Zhao F, $\mathrm{Hu}$ D, Sun Y: Prevalence of dyslipidemia and associated factors among the hypertensive rural chinese population. Arch Med Res, 2007; 38: 432-439

6) Wu JY, Duan XY, Li L, Dai F, Li YY, Li XJ, Fan JG: Dyslipidemia in Shanghai, China. Prev Med, 2010; 51: 412415

7) Fu YY, Yu JM, Wang JH, Wang JS, Sun YH, Liu HF, Hu DY: Prevalence and awareness of dyslipidemia among overweight and obese population in Beijing community. Chin J Cardiol, 2010; 38: 562-566

8) $\mathrm{He} \mathrm{J,} \mathrm{Gu} \mathrm{D,} \mathrm{Reynolds} \mathrm{K,} \mathrm{Wu} \mathrm{X,} \mathrm{Muntner} \mathrm{P,} \mathrm{Zhao} \mathrm{J,}$ Chen J, Liu D, Mo J, Whelton PK: Serum total and lipoprotein cholesterol levels and awareness, treatment, and control of hypercholesterolemia in China. Circulation, 2004; 110: 405-411

9) Joint Committee for Developing Chinese Guidelines on Prevention and Treatment of Dyslipidemia in Adults: Chinese guidelines on prevention and treatment of dyslipidemia in adults. Chin J Cardiol, 2007; 35: 390-419

10) Ainsworth BE, Haskell WL, Leon AS, Jacobs DJ, Montoye HJ, Sallis JF, Paffenbarger RJ: Compendium of phys- 
ical activities: classification of energy costs of human physical activities. Med Sci Sports Exerc, 1993; 25: 71-80

11) Yang G, Ma J, Liu N, Zhou L: Smoking and passive smoking in Chinese, 2002. Chin J Epidemiol, 2005; 26: 77-83

12) Department of Chronic Diseases and Health Promotion: Global Physical Activity Questionnaire Analysis Guide. WHO, available at http://www.who.int/chp/steps/GPAQ/ en/index.html

13) Wu Y, Huxley R, Li L, Anna V, Xie G, Yao C, Woodward M, Li X, Chalmers J, Gao R, Kong L, Yang X: Prevalence, awareness, treatment, and control of hypertension in China: data from the China National Nutrition and Health Survey 2002. circulation, 2008; 118: 2679-2686

14) Wang S, Xu L, Jonas JB, You QS, Wang YX, Yang H: Prevalence and associated factors of dyslipidemia in the adult chinese population. PLoS One, 2011; 6: e17326

15) Ruixing Y, Qiming F, Dezhai Y, Shuquan L, Weixiong L, Shangling P, Hai W, Yongzhong Y, Feng H, Shuming Q: Comparison of demography, diet, lifestyle, and serum lipid levels between the Guangxi Bai Ku Yao and Han populations. J Lipid Res, 2007; 48: 2673-2681

16) Cohen JD, Cziraky MJ, Cai Q, Wallace A, Wasser T, Crouse JR, Jacobson TA: 30-year trends in serum lipids among United States adults: results from the National Health and Nutrition Examination Surveys II, III, and 1999-2006. Am J Cardiol, 2010; 106: 969-975

17) Farzadfar F, Finucane MM, Danaei G, Pelizzari PM, Cowan MJ, Paciorek CJ, Singh GM, Lin JK, Stevens GA, Riley LM, Ezzati M: National, regional, and global trends in serum total cholesterol since 1980: systematic analysis of health examination surveys and epidemiological studies with 321 country-years and 3.0 million participants. Lancet, 2011; 377: 578-586

18) Li LM, Rao KQ, Kong LZ, Yao CH, Xiang HD, Zhai FY, Ma GS, Yang XG: A description on the Chinese national nutrition and health survey in 2002. Chin J Epidemiol, 2005; 26: 478-484

19) Tao S, Li Y, Xiao Z, Cen R, Zhang H, Zhuo Y, Zhou B, Chen P, Li Y, Liao Y, Et A: Serum lipids and their correlates in Chinese urban and rural populations of Beijing and Guangzhou. PRC-USA Cardiovascular and Cardiopulmonary Epidemiology Research Group. Int J Epidemiol, 1992; 21: 893-903

20) Tseng CH, Chong CK, Chan TT, Bai CH, You SL, Chiou HY, Su TC, Chen CJ: Optimal anthropometric factor cutoffs for hyperglycemia, hypertension and dyslipidemia for the Taiwanese population. Atherosclerosis, 2010; 210:
585-589

21) Jeong SK, Seo MW, Kim YH, Kweon SS, Nam HS: Does waist indicate dyslipidemia better than BMI in Korean adult population? J Korean Med Sci, 2005; 20: 7-12

22) Petrella RJ, Merikle E: A retrospective analysis of the prevalence and treatment of hypertension and dyslipidemia in Southwestern Ontario, Canada. Clin Ther, 2008; 30: 11451154

23) Oka R, Kobayashi J, Miura K, Nagasawa S, Moriuchi T, Hifumi S, Miyamoto S, Kawashiri MA, Nohara A, Inazu A, Takeda Y, Mabuchi H, Yagi K, Yamagishi M: Difference between fasting and nonfasting triglyceridemia; the influence of waist circumference. J Atheroscler Thromb, 2009; 16: 633-640

24) Gould AL, Davies GM, Alemao E, Yin DD, Cook JR: Cholesterol reduction yields clinical benefits: meta-analysis including recent trials. Clin Ther, 2007; 29: 778-794

25) Ford ES, Mokdad AH, Giles WH, Mensah GA: Serum total cholesterol concentrations and awareness, treatment, and control of hypercholesterolemia among US adults: findings from the National Health and Nutrition Examination Survey, 1999 to 2000. Circulation, 2003; 107: 21852189

26) Yoon SS, Carroll MD, Johnson CL, Gu Q: Cholesterol management in the United States: the national health and nutrition examination survey, 1999 to 2006. Ann Epidemiol, 2011; 21:318-326

27) Carroll MD, Lacher DA, Sorlie PD, Cleeman JI, Gordon DJ, Wolz M, Grundy SM, Johnson CL: Trends in serum lipids and lipoproteins of adults, 1960-2002. JAMA, 2005; 294: 1773-1781

28) Arao T, Oida Y, Maruyama C, Mutou T, Sawada S, Matsuzuki $H$, Nakanishi Y: Impact of lifestyle intervention on physical activity and diet of Japanese workers. Prev Med, 2007; 45: 146-152

29) Al-Mahmood AK, Ismail AA, Rashid FA, Azwany YN, Singh R, Gill G: Effect of therapeutic lifestyle changes on insulin sensitivity of non-obese hyperlipidemic subjects: preliminary report. J Atheroscler Thromb, 2007; 14: 122127

30) Lee MJ, Popkin BM, Kim S: The unique aspects of the nutrition transition in South Korea: the retention of healthful elements in their traditional diet. Public Health Nutr, 2002; 5: 197-203

31) Frank L, Kavage S: A national plan for physical activity: the enabling role of the built environment. J Phys Act Health, 2009; 6 Suppl 2: S186-S195 